\title{
Blood glucose control in diet controlled gestational diabetics (GODM A1) following corticosteroid administration
}

\author{
Kristine Van Kirk, $\mathrm{MD}^{1}$ Diedre Fleener, $\mathrm{RN}^{1}$ Asha Rijhsinghani, $\mathrm{MD}^{1}$ \\ Keywords: blood glucose; corticosteroids; diabetes, gestational; pregnancy
}

\section{OBJECTIVE}

To study the effect of corticosteroids on glucose control in preterm pregnant patients with diet controlled gestational diabetes, and to formulate a plan for surveillance and treatment in order to reduce maternal and neonatal morbidity.

${ }^{1}$ Department of Obstetrics and Gynecology, Carver College of Medicine, University of lowa Hospitals and Clinics, lowa City, IA, 52242

\section{METHODS}

This retrospective study was approved by the University of lowa Hospital and Clinics (UIHC) Institutional Review Board. All diet controlled gestational diabetic patients admitted to our hospital from 2005-2010 with singleton or multiple gestations receiving corticosteroids for fetal lung maturity at 24-37 weeks gestation were included. Data including gestational age at time of administration of corticosteroids, time interval from corticosteroid administration to rise in blood glucose, hypoglycemic agent if used and length of treatment, gestational age at delivery, and maternal characteristics such as age, BMI, and parity were collected by chart review. Statistical analysis was done using a computerized database, constructed and analyzed with WinStar software, release 1.70 (Anderson Bell, Arvada, CO).

\section{RESULTS}

A total of 3210 patients were admitted to UIHC at a preterm gestational age and 309 of those patients were diabetic by ICD-9 code. Ninety-six patients were eligible for the study in that they had an official diagnosis of diabetes and there was record of corticosteroid administration and blood glucose monitoring. Of these 96 patients, 34 patients had GODMA1. Five of these patients had normal blood sugars after receiving corticosteroids and 29 subjects had abnormal blood sugars. Six of the 29 patients with abnormal blood sugars did not receive treatment because their blood sugars were not deemed high

Please cite this paper as: Van Kirk K, Fleener D, Rijhsinghani A. Blood glucose control in diet controlled gestational diabetics (GODM A1) following corticosteroid administration. Proc Obstet Gynecol. 2012 ;2(3):Article 6 [ 2 p.]. Available from: http://ir.uiowa.edu/pog/. Free full text article.

Corresponding author: Donna Santillan, Department of Obstetrics and Gynecology, University of lowa, 463 MRF, 200 Hawkins Drive, lowa City, IA 42242. donna-santillan@uiowa.edu. 
enough to require treatment. Twentythree patients received treatment for sustained hyperglycemia. Two patients were treated with glyburide only and the remaining patients required insulin. Three patients received glyburide and subcutaneous insulin. Twenty-four patients required some form of insulin. The interval from corticosteroid administration to blood glucose elevation was 1 hour to 36 hours. In all but 2 patients, the treatment was continued until delivery. The gestational age in patients that required treatment for hyperglycemia $(31.77+/-2.5$ weeks) was significantly greater than those not requiring treatment $(30.0+/-3.3$ weeks). The mean number of days from corticosteroids to delivery was 9 days. The gestational age at delivery was also significantly greater in those requiring treatment $(33.35+/-2$ weeks) compared to those without treatment (31.57+/-3.45 weeks). Maternal BMI did not differ significantly between treated and non-treated patients. Maternal age was not significantly different between the two groups either.

\section{CONCLUSION}

Women with GODMA1 receiving corticosteroids will often develop hyperglycemia requiring treatment with oral agents or insulin. Close monitoring of blood glucose levels is important for timely initiation of treatment. Providers should have a low threshold to initiate treatment. Patients with more advanced gestational age are likely to require more aggressive treatment. Controlling maternal blood glucose carefully in GODMA1 patients is important for improved perinatal outcome. The best treatment regimen has not been established, but will likely involve insulin. 